Makale Gönderim Tarihi / Received: 20.06.2017

Makale Yayımlanma Tarihi / Publication: 15.12.2017
Makale Kabul Tarihi / Accepted: 03.12.2017

Aralık/December $2017 \cdot 7(3) \cdot 684-696$

\title{
Türkiye'de Yayınlanmış FeTeMM Eğitimi İle İlgili Çalışmaların İncelenmesi
}

\section{Review of STEM Studies Published in Turkey}

Şule ELMALI*

\author{
Fatime BALKAN KIYICI ${ }^{* *}$
}

Öz. Bu çalışmanın amacı Fen Teknoloji Mühendislik ve Matematik yaklaşımı (FeTeMM) içerikli makaleleri ve lisansüstü çalışmaları yöntem ve konu eğilimi bakımından incelemektir. Bu doğrultuda, araştırmada yer alan çalışmalar Ulusal Akademik Ağ ve Bilgi Merkezi (ULAKBiM), Education Resources Information Center (ERIC), EBSCO Host, International Scientific Indexing (ISI) Web of Science ve Scopus veritabanları tarafından taranan ve internet üzerinden erişime açık olan 30 makale ve ikisi kısıtlı erişimde bulunmak üzere, 5 lisansüstü tez çalışmasından oluşmaktadır. Araştırmada, doküman incelemesi yöntemi kullanılmıştır. Incelenen çalışmalar, araştırma modeli, çalışma grubu, veri toplama araçları, veri analiz yöntemi ve araştırma konusu içerikleri açısından analiz edilmişlerdir. Sonuç olarak, çalışmaların kuramsal temelli olarak yapıldığı, deneysel çalışmaların ise genellikle bir proje ürünü olarak ortaya çıktığı görülmektedir. Bu çalışmanın, FeTeMM eğitimi alanında yapılacak araştırmalarda, Türkiye'de yapılan çalışmaların içeriği hakkında bilgi vermesi ve mevcut eğilimleri göstermesi açısından konuyla ilgili yapılacak çalışmalara fikir vereceği düşünülmektedir.

Anahtar Kelimeler: Betimsel analiz, FeTeMM, literatür inceleme, doküman analizi.

\begin{abstract}
The purpose of the study is to examine the articles and dissertations about Science, Technology, Engineering Mathematics (STEM) approach in terms of method and subject trend. Accordingly, the studies in this research consist of 30 papers which can be accessible via the internet and indexed by ULAKBIM, ERIC, EBSCO Host, ISI Web of Science and Scopus indexes and also 5 thesis and dissertations 2 of them are restricted. This study was conducted with qualitative document analysis method. The researches examined in the study were analyzed in terms of research model, study group, data collection tools, data analysis, method and research content. This study is thought to be helpful in informing about the contents of studies conducted in Turkey and showing current trends in the field of STEM education.
\end{abstract}

Keywords: Descriptive analysis, STEM, literature review, document analysis.

\section{Toplumsal Mesaj.}

Araştırmada Türkiye'de ve dünyada popüler bir konu olan FeTeMM yaklaşımına bağlı olarak yürütülen çalışmaların Türkiye'de nasıl ele alındığıyla ilgili bilgi sahibi olmak istenmiştir. Yapılan çalışmaların yöntem kısmında çeşitli eksiklikler bulunduğu ve FeTeMM kapsamında yürütülen içerik anlayışında büyük farklılıklar bulunduğu sonuçlarına ulaşılmıştır.

Public Interest Statement. In this study, it is claimed to have konowledge about how the studies carried out in relation to the STEM approach, which is a popular subject in both Turkey and in the world, are handled in Turkey. There are various deficiencies in the method part of the works done and there are big differences in content understanding carried out within STEM.

\footnotetext{
${ }^{*}$ Arş. Gör., Sakarya Üniversitesi, Eğitim Fakültesi, Matematik ve Fen Bilimleri Eğitimi Bölümü, suleelmali@sakarya.edu.tr

** Doç. Dr., Sakarya Üniversitesi, Eğitim Fakültesi, Matematik ve Fen Bilimleri Eğitimi Bölümü, fbalkan@sakarya.edu.tr 


\section{GiRiş}

Ülkelerin birbirleriyle sağlıktan bilime, sanattan tıpa, ekonomiden eğitime kadar pek çok alanda sürekli bir rekabet içinde olduğu ve teknoloji çağı olarak adlandırılan günümüzün hızlı değişen dünyasında bilim eğitimi ve öğretiminin etkili olarak yürütülmesi eğitimin en önemli hedeflerinden biri olarak karşımıza çıkmaktadır. Eleştirel düşünebilen, sorgulama becerisine sahip ve özgüveni yüksek bireylerin yetişmesi, ancak bilimsel bir bakış açısına sahip olma sonucunda mümkün olur. Söz konusu insan profilinin yetişmesi, eğitimde çağdaş ve güncel olmayı zorunlu kıldığından, toplumda bilimsel düşünme becerisinin yerleşmesi, bilime yönelik bilinç ve farkındalığın artması, bilim kültürünün yaygınlaşması gerekmektedir. Bu durum, ülkemizin geleceği açısından nitelikli bireylerin yetiştirilerek topluma kazandırılması noktasında en büyük paylardan birinin eğitime ait olduğunu ortaya koymaktadır. Ülkemizde eğitim konularına ilişkin birçok sorun bulunmaktadır. Bu durumlardan başlıca ve sık tartışılanlarından biri, OECD tarafından düzenlenen TIMSS ve PISA gibi uluslararası sınavlarda Türkiye'nin genel olarak eğitimde beklenen başarıyı gösterememesi ve yıllara göre başarı sıralamasında önemli bir değişiklik meydana getirememesidir. Bu sınavlarda ülkemizdeki öğrenciler okuma, matematik ve fen alanlarının tümünde OECD ülkelerinin ortalamalarının altında kalmıştır (MEB, 2013a; OECD,2016).

Bu durum pek çok kez araştırma konusu olmuş, önlem için çeşitli programlar, yöntemler işe koşulmuştur. Bilimsel anlayışın ve düşüncenin gelişmesinde en önemli unsurlardan biri olan fen bilimleri dersi yıllar içinde öğretim programları düzeyinde revizyonlar geçirerek, istisnasız her bireyin fen okuryazarı olarak yetişmesi gereği vurgulanmıştır (MEB, 2013b). Günümüz dünyasının problemlerinin üstesinden gelebilmek amacıyla kullanılan en sık ve doğru bilgi türü bilimsel bilgi olup, bilimsel bilgi başı başına birçok bakış açısına sahip olmayı gerektirir. Mevcut fen bilimleri dersi öğretim programında disiplinler arası ilişki kurabilme, çok yönlü düşünebilme, problem çözebilme gibi özelliklerle araştırma sorgulama yaklaşımını esas alınan yapılandırmacı eğitim uygulanmaktadır. Ancak eğitim ortamlarında uygulamada sıklıkla bu durum mümkün olamamaktadır. Çünkü okul müfredatında dersler sıklıkla birbirinden bağımsız ve kopuk şekilde yürütülmektedir (Karahan ve Canbazoğlu-Bilici, 2014, s.95). Oysa ki, günlük hayattaki problemlere çözüm bulabilme noktasında birçok disiplinin gerektirdiği bakış açılarına ve becerilere sahip olmaya intiyaç vardır. Bu sorunun üstesinden gelmek amacıyla en yeni yaklaşımlardan biri olarak dünyada olduğu gibi ülkemizde de eğitim alanında derslerin FeTeMM yaklaşımıyla yürütülmesi ve etkisine ilişkin çalışmalar yapılması önerisi karşımıza çıkmaktadır (Çorlu,2014; Akgündüz, 2016; Bozkurt Altan ve Ercan, 2016).

Günlük hayatta karşılaşılan problemlerin çözümünde izlenen yol genellikle fen, teknoloji, matematik ve mühendislik becerilerini içermektedir (National Research Council, 2005; 2011). Bu bağlamda tüm dünyada olduğu gibi ülkemizde de disiplinler arası ilişkinin keşfedilmesine, anlamlı öğrenmelerin sağlanmalarına imkan sunan ve yöntemin doğası gereği uygulamalı etkinliklerin olduğu, öğrencinin aktif ve merkezde kılan FeTeMM yaklaşımı temelli uygulamaya yönelik etkinlikler geliştirilmeye başlanmıştır. FeTeMM eğitimi, bir ünite ya da dersi gerçek yaşam problemlerindeki örnekler üzerinden ders içeriğiyle ilişki kurularak bu süreçte fen, matematik, teknoloji ve mühendislik disiplinlerinin kaynaştırılarak kullanılmasını hedefler (Bozkurt, 2014). Bununla beraber, ilk ve ortaöğretim seviyesindeki fen ve matematik standartlarının yükseltilmesi, öğrencilerin fen, teknoloji, mühendislik ve matematik alanlarına yönelmesini destekler. Bu doğrultuda Ramaley (2007), fen ve matematik müfredatlarının teknoloji ve mühendislik entegrasyonu ile çok disiplinli bir yapıda olması gerektiğini belirtmiştir (Karahan ve CanbazoğluBilici, 2014, s.95). Böylelikle öğretmenin FeTeMM uygulamalarını öğrenme ortamında aktif bir şekilde yürütebilmesi için ilgili alan bilgisine, pedagojik içerik bilgisine ve teknolojik pedagojik içerik bilgisine sahip olması amaçlanır (NRC 2011; Marino, Black, Hayes ve Beecher 2010; Bozkurt, 2014). Ancak, FeTeMM eğitimiyle ilgili yaşanan temel problem uygulamaların sınıf içinde nasıl gerçekleştirileceğinin net olmaması ve öğretmenlere bu konuda rehberlik etme imkanının sınırlı olması konusudur (Pitt,2009; Bybee, 2010; Roberts ve Cantu, 2012; Ercan, Altan, Taştan ve Dağ, 
2015). FeTeMM eğitimi mevcut öğretim programlarındaki anlayışın etkisi doğrultusunda, yalnızca fen ve matematik dersiyle ilişkili bir yaklaşım olarak değerlendirilmekte ve öğrencilerin bu alanlarda akademik başarılarının artış göstermesi şeklinde yorumlanmaktadır. Öğretim programlarında bu derslerin ayrı ayrı okutulması ve teknoloji derslerinin sınırlı olmakla birlikte mühendislik boyutuna ait bir ders yürütülmemesi durumu böyle bir sonuca yol açmaktadır (Bozkurt Altan, Yamak ve Buluş Kırıkkaya, 2016). Teknoloji ve mühendislik becerileri, bu içeriğin diğer parçaları olmakla birlikte, günümüz ve geleceğimizde yaşanan enerji tasarrufu, çevre korunumu ve sağlık gibi temel problemlerle başa çıkmakta doğrudan ön planda olan becerilerdir (Bybee, 2010; Öner ve Capraro, 2016). Bu doğrultuda, FeTeMM eğitimine yönelik uygulamaların verimli bir şekilde yürütülmesi adına bu alanda yapılan çalışmaları incelemek ve ülkemizde yürütülen çalışmaların incelenmesi gerekmektedir.

FeTeMM eğitimi, 21. Yüzyıl becerilerinden, yenilikçi ve yaratıcı düşünme ile inovasyon yapabilme becerisine sahip bir nesil yetiştirmeyi hedefleyen ülkeler tarafından benimsenmiştir (Bybee, 2010). Wagner (2008)'e göre ise, 21. Yüzyıl becerisine sahip bir öğrenci, bilgiyi yalnızca hatırlamaktan öte bilgileri yeni bir duruma uyarlama becerisi olarak tanımlamıştır. Bu bağlamda sahip olunması gereken bu becerileri 7 bağlamda ele almıştır. Eleştirel düşünme ve problem çözme, iş birliği yapabilme, yeni gelişen durumlara uyum sağlayabilme, girişimcilik, etkili sözlü ve yazıı iletişim kurabilme, bilgiyi analiz etme ve değerlendirme, merak ve yaratıcılık gibi beceriler şeklinde tanımlamıştır. Bu becerilerin, öğrencilerin pek çok yönden gelişimini desteklemesi, ülkemizde yürütülen FeTeMM çalışmalarının, 2014 yılından sonra hız kazanmasına neden olmuştur. Bu bağlamda, bu çalışmada ülkemizdeki FeTeMM eğitiminin ele alınış biçimi, çalışmaların amacı ve yöntemlerinin incelemesi yapılmıştır. FeTeMM eğitiminin hem dünyada hem de ülkemizdeki öğretim programları üzerindeki etkisinin gittikçe önem kazanan bir duruma ulaştığı düşünüldüğünde, bu konudaki çalışmalara yol gösterecek nitelikte alanyazın incelemesi, ülkemizdeki konuya ilişkin araştırma problemlerinin ele alınış biçimlerini ve yöntem eğilimlerinin belirlenmesi gereği öne çıkmaktadır. FeTeMM eğitiminin ülkelerin öğretim programlarında yer bulmasıyla birlikte uluslararası çalışmalarla ilgili çeşitli alanyazın tarama çalışmaları yapıımıştır. Jayarajah, Mohd Saat ve Abdul Rauf (2014) Malezya'daki FeTeMM eğitimiyle ilgili alanyazın taraması amacıyla yaptıkları çalışmada 1999 ile 2013 yılları arasında ERIC veritabanında taranan 57 makaleyi incelemişlerdir. Henderson, Beach ve Finkelstein (2011) tarafından Web of Science ve ERIC veritabanlarında 1995- 2008 yılları arasında yayınlanan 300 makaleyi incelemişlerdir. Akgündüz (2016) ise, 2000-2014 yılları arasında Türkiye'de üniversite sınavı sonuçlarına göre en yüksek puanı alan ilk 1000 öğrencinin kapsama alındığı toplam 17135 öğrencinin FeTeMM alanlarına göre meslek tercihlerinin nasıl olduğuna ilişkin bir çalışma yapmıştır.

\subsection{Amaç}

Bu çalışmada, dünyada olduğu gibi Türkiye'de de son yıllarda oldukça popüler bir konu olan ve yayın sayısı gün geçtikçe artış gösteren FeTeMM içerikli makaleleri ve lisansüstü çalışmaları konu alanı ve araştırmalarda tercih edilen yöntem bakımından incelemek amaçlanmıştır. Bu doğrultuda, ULAKBIM, ERIC, EBSCOHost, ISI Web of Science ve Scopus veri tabanlarında yapılan taramada Ağustos, 2013 ve Aralık 2016 tarihleri arasında yayınlanmış olan 30 makale ve YÖK Ulusal Tez Merkezi tarafından taranan 5 lisansüstü teze ulaşılmış ve betimsel analiz yöntemiyle incelenmiştir. Bu çalışmanın, FeTeMM eğitimi alanında yapılacak araştırmalarda, Türkiye'de yapılan çalışmaların içeriği hakkında bilgi vermesi ve mevcut eğilimleri göstermesi açısından önemli olacağı düşünülmektedir.

\subsection{Problem}

1. Ülkemizde FeTeMM eğitimi kapsamında yapılan araştırmalar hangi bağlamlarda ne tür yöntemler (araştırma metodu, örneklem, veri toplama araçları) kullanılarak gerçekleştirilmiştir?

2. Ülkemizdeki FeTeMM eğitimi araştırmalarında ele alınan araştırma konuları nelerdir? sorularına odaklanılmıştır. 


\section{YÖNTEM}

Çalışmada FeTeMM eğitimi ile ilgili yayınlanmış çalışmaların içeriğindeki yönelimin eğilimini belirlemek amaçlandığı için doküman incelemesi yapılmıştır. Doküman incelemesi; hedeflenen olgu veya olaylarla ilgili bilgi içeren yazılı materyallerin analizini kapsar ve tek bir veri toplama yöntemi olarak kullanılabileceği gibi, diğer ver toplama yöntemleriyle birlikte de kullanılabilir (Yıldırım ve Şimşek, 2013). Son yıllarda fen eğitimi ile ilgili çalışmalarda disiplinler arası konuları araştırmaya yönelik eğilim olduğu ve bu intiyaca yönelik olarak FeTeMM eğitimi bağlamında ele alınarak, konuyla ilgili çalışmaların sayısında hızı bir artış olduğu görülmektedir. Bu çalışmayla da eğilimin nasıl gerçekleştiğiyle ilgili veriye ulaşıımak istendiğinden doküman inceleme yöntemi kullanılmıştır.

\section{1 Çalışma Grubu/Evren/Örneklem}

Araştırmaların çoğunluğu nitel çalışmalardan oluşmakta olup, az sayıda nicel çalışma da bulunduğundan kitle, çalışma grubu, evren ve örneklem başlıkları altında ele alınmıştır. Çalışmalardan 2 tanesi ölçek geliştirme çalışması olup 8 tanesi ortaokul öğrencileri, 7 çalışma öğretmen adaylarıyla, 1 çalışma ortaöğretim öğrencileriyle gerçekleştirilmiştir. Çalışmalardan bir tanesi öğretmenlerle bir proje kapsamında yürütülmüş olup, bir çalışmada ortaöğretim öğrenci grubuyla gerçekleştirilmiştir. Aynı zamanda, bir çalışmada matematik, bilgisayar ve endüstri mühendisliği 1. Sınıf öğrencileriyle gerçekleştirilen FeTeMM projesinin FeTeMM kariyer alanlarında öğrenim gören öğrenciler tarafından nasıl algılandığına yönelik olarak gerçekleştirilmiştir.

\subsection{Veri Toplama Yöntemi}

Bu araştırmanın verileri, FeTeMM eğitimi ile ilgili yayınlanmış çalışmalara ait dokümanlardan elde edilmiştir. Araştırma sürecinin ilk aşamasında makale seçme kriterleri ve anahtar kelimeler belirlenmiştir. Makalelerin seçiminde, Google Akademik arama motorunda anahtar kelimeler ile sorgular yürütülmüş ve ardından, ULAKBiM, ERIC, EBSCOHost, ISI Web of Science ve Scopus indeksleri tarafından taranan ve Ağustos, 2013 ve Aralık 2016 tarihleri arasında yayınlanmış olan 30 makale ve YÖK Ulusal Tez Merkezi tarafından taranan 5 lisansüstü tez, betimsel analiz yöntemiyle incelenmiştir. Bu doğrultuda Türkiye'de FeTeMM eğitimini tanımlamada kullanılan anahtar sözcükler Türkçe ve İngilizce dillerinde tanımlanarak aramalar gerçekleştirilmiştir. Alanyazın taraması yapılırken kullanılan anahtar sözcükler olarak "FeTeMM", "FeTeMM eğitimi", "Stem Education", Stem Education and Turkey" gibi anahtar kelimelerle tarama süreci gerçekleştirilmiştir.

\subsection{Verilerin Analizi}

Veriler, anahtar kelimeler ve belirlenen kriterler doğrultusunda elde edilen çalışmalardan, araştırma konusu eğilimleri, yöntemi (araştırma modeli, çalışma grubu, veri toplama araçları, veri toplama süreci ve veri analizi) yönünden incelenerek analiz edilmiştir. Araştırmada FeTeMM eğitimi ile ilgili yayınlanmış çalışmalara ait dokümanlardan elde edilen verilere betimsel analiz yapılmıştır. Betimsel analizde amaç, elde edilen bulguları düzenlenmiş ve yorumlanmış bir biçimde sunmaktır (Yıldırım ve Şimşek, 2013). Sınıflandırmanın sonunda oluşan veriler betimsel istatistik yöntemlerinden frekans tablosu oluşturularak sunulmuştur. Dergilerin isimleri ve makalelerin hangi yıllar arasında yayınlandığı ise ekte sunulmuştur.

\section{BULGULAR}

Çalışmalar lisansüstü araştırmalar ve dergilerde yayınlanan araştırma makalelerin FeTeMM eğitimi konu eğilimleri ve araştırmalarda kullanılan yöntemler bakımından iki ayrı başlık altında incelenmiştir.

\subsection{FeTeMM Eğitimi Araştırmalarında Yöntem}

Bu araştırma kapsamında incelenen çalışmalarda FeTeMM eğitimi araştırmaları, çeşitli araştırma yöntemleri ve veri toplama araçları kullanılarak araştırılmıştır. İncelenen uygulama temelli 20 araştırma makalelesinde kullanılan yöntemlerinin nicel, nitel ve karma desenli araştırmalar olmak üzere üç grupta toplanırken, nitel araştırmaların çoğunlukta olduğu ve bu çalışmalarda, durum 
çalışmalarının tercih edildiği, az sayıda çalışmada ise nicel ve karma yöntemlerin yer aldığı tespit edilmiştir. Kullanılan veri toplama araçlarının sıklıkla yazarlar tarafından geliştirilen etkinliklerden meydana geldiği görülmüştür. Uygulamalı çalışmalarda, bir proje kapsamında yürütülen etkinliklerin ilgili çalışma grubu üzerindeki akademik başarı, tutum, ilgi ve görüşleri üzerine etkisine yönelik olarak yoğunlaştığı görülmektedir. Ayrıca FeTeMM yaklaşımı temelli geliştirilen etkinliklerin öğretmenler ve öğretmen adaylarına farkındalık kazandırma ve yeterlik durumlarına yönelik algılarının tespitinin yapılmaya çalışıldığı görülmektedir.

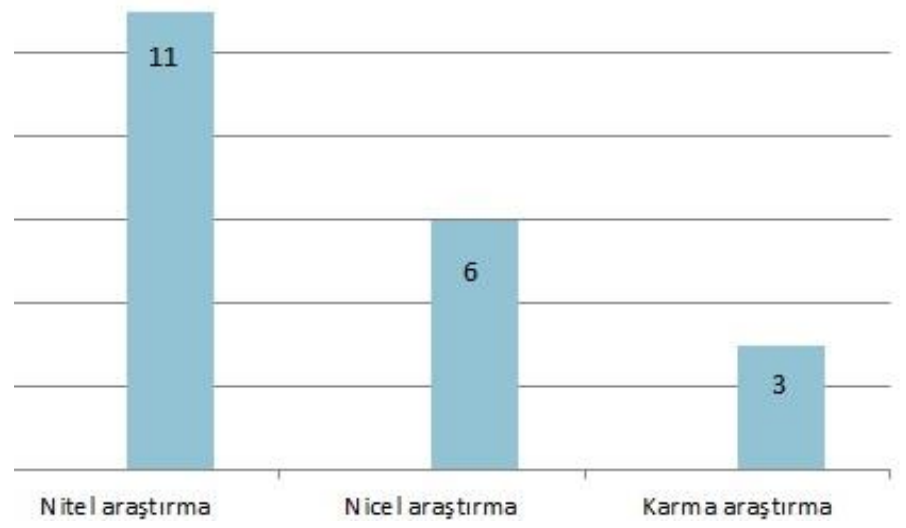

Şekil 1. Araştırmalarda kullanılan yöntem sayısına ilişkin sütun grafiği

\subsubsection{FeTeMM Eğitimi Araştırmalarında Kullanılan Araştırma Modelleri}

FeTeMM eğitimi kapsamında yapılan uygulamalı araştırmalarda çalışmaların çoğunluğunu nitel araştırmalar oluşturmaktadır. Bu çalışmalar kapsamında kullanılan modeller ise, 4 durum çalışması, 3 tarama modeli, çalışmaların her birinden birer tane olmak üzere ön test son test tek gruplu deneysel desen, açıklayıcı karma desen, iç içe gömülü desen, fenomenolojik araştırma deseninde yürütülmüştür. İncelenen 7 çalışmada ise araştırma modellerinin türü belirtilmemiş yalnızca yöntemin nitel, nicel ya da karma olduğuyla ilgili bilgi verilmiştir.

\subsubsection{Veri Toplama Araçları}

Araştırma kapsamındaki makalelerde kullanılan veri toplama araçları incelendiğinde 4 çalışmada açık uçlu soru formu, 4 çalışmada görüşme formu ya da kayıtları, 2 çalışmada aktivite değerlendirme formu, 2 çalışmada kelime ilişkilendirme testi ve her çalışmada birer tane olmak üzere saha notları, proje raporları, sınav kağıtları gözlem, öğrenci günlükleri ve zihin haritasından veri toplama aracı olarak kullanılmıştır. Toplam 5 çalışmada ise likert tipli ölçekten veri toplama aracı olarak yararlanılmıştır.

\subsubsection{Verilerin Toplanması ve Analizi}

Makalelerde kullanılan analiz teknikleri incelendiğinde, 20 çalışmadan 6 tanesinde nicel analizlerin yapıldığı görülmüştr. Bu çalışmaların, 1 tanesinde nicel parametrik analiz tekniklerinden t-testi, 1 tanesinde varyans analizi (ANOVA), 2 çalışmada betimsel istatistikler kullanılmakla birlikte, 2 ölçek geliştirme çalışmasında ise faktör analizi kullanılmıştır. Nitel ve karma yöntemin kullanıldığı belirtilen toplam 14 makalede ise çalışma kapsamında kullanılan dokümanlardan ve görüşmelerden elde edilen bulgulardan yola çıkılarak kodlamalar yapılmış, betimsel ve içerik analizleri yürütülmüştür.

\subsection{FeTeMM Eğitimi Araştırmalarında Konu Eğilimleri}

Analizi gerçekleştirilen çalışma doğrultusunda ülkemizde FeTeMM araştırmalarının yaklaşık 2013 yılında gerçekleştirilmeye başlandığı ve bu alandaki çalışmaların her geçen yıl, önceki yıla göre artış gösterdiği tespit edilmiştir. 2013 yılında bir adet ve kuramsal temeli bir araştırma olan araştırma sayısı, 2014 yılında dört, 2015 yılında yedi, 2016 yılında 18 olarak belirlenmiştir. Araştırmalar çoğunlukla öğretmen adayları ile gerçekleştirilmiştir. Incelenen 30 araştırmanın 10 tanesi kuramsal içerikli olup, 20 tane deneysel çalışmanın ağırlıklı olarak ortaokul düzeyindeki öğrencilerle 
gerçekleştirilmiş olduğu görülmektedir. Bu çalışmalarda, FeTeMM eğitimi uygulamalarının öğrencilerin akademik başarı, FeTeMM kariyer mesleklerine yönelik tutumları ve FeTeMM farkındalıklarının artırılmasına yönelik etkisi incelenmiştir. Araştırma makalelerine ilişkin dokümanların analizinden elde edilen bulgular ise, deneysel temelli araştırmalar ve kuramsal temelli araştırmalara yönelik konu eğilimleri başlığı altında iki ayrı tabloda sunulmuştur.

Tablo 1. Uygulama Temelli Araştırmaların Konu Eğilimleri

\begin{tabular}{lc}
\hline & Frekans \\
\hline FeTeMM eğitimi programının öğretmen eğitiminde kullanımı, yeterlik ve algı & 2 \\
çalışması & \\
Çevre eğitiminde FeTeMM yaklaşımının uygulamalarına yönelik öğrenci & 2 \\
görüşleri & \\
Okul dışı FeTeMM eğitimi uygulamalarına yönelik öğrenci görüşleri & 1 \\
Mühendislik tasarım döngüsünü kullanarak televizyon kanallarında & 1 \\
gösterilecek bir FeTeMM spotu tasarlama ekinliği & \\
FeTeMM Farkındalık Ölçeği (FFÖ) geliştirme, geçerlik ve güvenirlik çalışması & 1 \\
FeTeMM temelli ders planı örneği geliştirme & 1 \\
Disiplinlerarası eğitim anlayışına FeTeMM eğitimi uygulamalarının etkisi & 1 \\
Fen ve matematik öğretmen adaylarının FeTeMM eğitimine yönelik görüşleri & 1 \\
Entegre Fetemm projesiyle öğrenci çıktılarının değerlendirilmesi & 1 \\
FeTeMM eğitiminde coğrafi bilgi sistemlerinin kullanımı & 1 \\
FETEMM ile ilgili bilişsel yapılarının ortaya çıkarılması & 1 \\
Entegre Fetemm öğretimi yönelim ölçeği formunun geçerlik ve güvenirlik & 1 \\
çalışması & \\
FETEMM'e yönelik tutum & 1 \\
Fen eğitiminde bilim ve mühendislik uygulaması: etkinlik örneği & 1 \\
Düşük sosyoekonomik seviyedeki öğrencilerin FeTeMM odaklı kariyer & 1 \\
mesleklerine olan ilgi ve tutumları & \\
5. sınıf öğrencilerinin bilimsel süreç becerileri ile fene karşı Tutumlarına & \\
FeTeMM Etkinliklerinin Etkisi & \\
Mühendislik tasarımı temelli uygulamaların öğrencilerin akademik başarıları & üzerine etkisi \\
Robotik ve mühendislik tasarımı uygulamalarının öğrencilerde FeTeMM kariyer \\
mesleklerine yönelik tercihlerine etkisi
\end{tabular}

Tablo 1'de uygulama temelli araştırmaların öğretmen, öğretmen adayları ve öğrencilerle gerçekleştirilen etkinliklerden oluştuğu görülmektedir. FeTeMM içeriğini oluşturan uygulamalı çalışmalarda yaklaşımın, akademik başarı, tutum ve görüşler üzerindeki etkisinin ortaya çıkarılması amaçlanarak yürütüldüğü söylenebilir.

Tablo 2. Kuramsal temelli araştırmaların konu eğilimleri ve frekans dağılımı

\begin{tabular}{lc}
\hline & Frekans \\
\hline FeTeMM eğitimi ve FeTeMM okulları tanıtımı & 2 \\
Matematiksel modellemeye entegre edilmiş FeTeMM uygulamaları & 1 \\
FeTeMM içerikli okul sonrası etkinlikler ve öğrenciler üzerindeki etkileri & 1 \\
2000-2014 yılları arasında üniversite sınavına giren öğrencilerin FeTeMM kariyer & 1 \\
alanlarına yönelik tercihleri & \\
Türkiye'de okul öncesi dönemde FeTeMM eğitimi & 1 \\
Türkiye'de üstün yetenekli öğrenciler ve FeTeMM eğitimi & 1 \\
FeTeMM eğitim ortamının özelliklerine yönelik öneriler & 1 \\
Akredite edilmiş bir yükseköğretim kuruluşunun FeTeMM alanlarında yürütülen & 1 \\
müfredatlarının incelenmesi & \\
FeTeMM eğitimi ve alan öğretmeni eğitimine yansımaları & 1 \\
\hline
\end{tabular}


Tablo 2'de FeTeMM eğitimi ile ilgili yapılan kuramsal temelli araştırmaların konu eğilimlerinin eğitim ortamı, farkı öğretim düzeyindeki öğrenciler için uygulanmasına yönelik görüşlerin yer aldığı görülmektedir. Ayrıca, FeTeMM eğitiminin içeriği ve yapısı hakkında bilgi verme amacına yönrlik olarak yapılan çalışmaların yer aldığı görülmektedir.

\subsection{Lisansüstü çalışmalarda kullanılan yöntem ve konu eğilimi}

Lisansüstü çalışmalar incelendiğinde çalışmaların üçü doktora tezi, diğer ikisi ise yüksek lisans tezidir. Lisansüstü çalışmalarda kullanılan yöntemlerde 3 çalışmada nicel araştırma yöntemi, 2 çalışmada ise karma araştırma yönteminin kullanıldığı görülmüştür. Doktora tez çalışmalarının birinde nicel yöntem, diğer ikisinde ise karma yöntem belirlenerek deneysel uygulamalar yürütülmüştür.

Tablo 3. Lisansüstü çalışmaların amaçlarına göre sınıflandırılması

\begin{tabular}{|c|c|c|}
\hline $\begin{array}{l}\text { Lisansüstü } \\
\text { çalışmalar }\end{array}$ & Konu eğilimi & Sıklık \\
\hline \multirow{3}{*}{ Doktora } & $\begin{array}{l}\text { FeTeMM etkinlikleri temelli yürütülen Fen Lab ve Uygulamaları } \\
\text { dersinde öğretmen adaylarının bilimsel süreç becerileri ve karar verme } \\
\text { becerilerine etkisi }\end{array}$ & 1 \\
\hline & $\begin{array}{l}\text { FeTeMM uygulamalarının, ilköğretim 7. sınıf öğrencilerinin Kuvvet ve } \\
\text { Hareket ünitesine yönelik akademik başarılarına, karar verme } \\
\text { becerilerine, mühendislik disiplinine yönelik görüş ve yeterliklerine } \\
\text { etkisi }\end{array}$ & 1 \\
\hline & $\begin{array}{l}\text { 7. sınıf fen bilimleri dersine entegre edilmiş FeTeMM uygulamaları ve } \\
\text { tam öğrenmenin etkilerinin öğrencilerin akademik başarıları, } \\
\text { sorgulayıcı öğrenme becerileri algılarına, motivasyonları, FeTeMM'e } \\
\text { karşı tutumlarına ve bilginin kalıcılı̆ına etkisi }\end{array}$ & 1 \\
\hline \multirow{3}{*}{$\begin{array}{l}\text { Yüksek } \\
\text { Lisans }\end{array}$} & $\begin{array}{l}\text { Asitler ve Bazlar konusunda FeTeMM temelinde hazırlanan öğretim } \\
\text { tasarımının uygulamasının 8.sınıf öğrencilerinin akademik başarılarına, } \\
\text { yaratııılık ve problem çözme becerileri üzerindeki etkisi }\end{array}$ & 1 \\
\hline & FeTeMM içerikli okul sonrası etkinliklerin yedinci sınıf öğrencilerinin & \\
\hline & $\begin{array}{l}\text { Kuvvet ve Hareket ünitesinin basit makineler konusundaki başarılarına, } \\
\text { mühendislik ve teknoloji kavramlarına yönelik anlayışlarına, FeTeMM } \\
\text { alanlarına dair tutumları ve ilgileri üzerindeki etkisi }\end{array}$ & 1 \\
\hline
\end{tabular}

Lisansüstü çalışmalarda, FeTeMM temelli etkinlikler oluşturularak, hazırlanan içeriklerin çalışma grubunun ilgi, tutum ve motivasyon gibi duyuşsal özeeliklerindeki değişimin incelenmesinin amaçlandığı görülmektedir. Aynı zamanda bu çalışmalarda, FeTeMM temelli etkinliklerin, öğrencilerin akademik başarıları, yaratıcılık, problem çözme ve karar verme gibi üst düzey bilişsel becerilerine etkisinin sorgulandığı görülmektedir.

\section{SONUÇ, TARTIŞMA ve ÖNERILER}

FeTeMM eğitiminde araştırmacıların kullandıkları yöntemler ve araştırmalardaki konu eğilimlerinin araştırıldığı bu çalışmada gelişen bir konu alanı olduğu için sınılı sayıda veri kaynağına ulaşılabilmiştir. Ancak konunun öneminin ve güncelliğinin vurgulanması üzerine, bu alanda yapılan çalışmalarda hız kazandığı ve artış yaşandı̆̆ı görülmektedir. Amerika Birleşik Devletleri'nde FeTeMM eğitimine verilen önemin etkileri ülkemizde de görülmeye başlamıştır. Bu doğrultuda eğitim çalışmalarının yanı sıra toplumda saygın bir yeri olan Türk Sanayici ve İşadamları Derneği (TÜSIAD) tarafından FeTeMM eğitiminin önemi ve FeTeMM işgücüne duyulan ihtiyacı ele alan FeTeMM Zirvesi düzenlenerek, iş dünyası ve üniversiteler arasında görüş alışverişi fırsatı yaratılmıştır (Bozkurt-Altan, Yamak ve Buluş-Kırıkkaya, 2016). Ayrıca yapılan çalışmaların bir kısmının TÜBITAK projesi kapsamında destekleniyor oluşu da bu konuya verilen önemin bir başka göstergesidir (Bozkurt-Altan ve Ercan,2016). Türkiye'de yapılan FeTeMM temelli çalışmaların, konu eğilimlerinin FeTeMM yaklaşımını temel alan etkinlikler geliştirilerek etkilerinin çeşitli boyutlardan 
irdelenmeye yönelik olarak gerçekleştirildiği görülmektedir. Bu bağlamda çalışlan her düzeydeki grupta tutum, motivasyon, ilgi gibi duyuşsal boyutlarda olumlu etkilerinin olduğu görülmektedir. Bunun yanı sıra öğrencilerin teknoloji bilgisinin gelişimine katkıda bulunulduğu ve özellikle ortaokul öğrencileriyle gerçekleştirilen çalışmaların, öğrencilerin kariyer seçimleri hususunda FeTeMM meslekleri yönünde eğilimler gösterdiklerini, öğrenmelerine katkıda bulundukları, işbirliği duygusunu geliştirdiği araştırmalardan çıkan sonuçlar arasındadır. Dolayısıyla, FeTeMM temelli araştırmalardan elde edilen sonuçların FeTeMM yaklaşımının hedefleriyle uyumlu olduğu söylenebilir. Aynı zamanda Milli Eğitim Bakanlığı'nın 2017 yılında öğretim programları revizyonu kapsamında yayınladığı Fen Bilimleri dersi öğretim programında FeTeMM yaklaşımına, uygulamalı bilim başlığı altında yer vererek hazırladığı yenilikler de bu noktada dikkat çekicidir (MEB,2017).

Kuramsal çalışmalarda genellikle FeTeMM temelli eğitimin ülkemizdeki tanınırlığını artırmaya ve geliştirmeye yönelik fırsatlar sağlanmasına ilişkin çağrıların yapıldığı hususu öne çıkmaktadır (Öner ve Capraro, 2016; Çorlu, Capraro ve Capraro, 2014; Çorlu, 2014). Konunun anlaşılırlığının ve uygulamasının sağlıklı olarak yürütülmesi adına uygulamalı örnekleri içeren modüller hazırlanmasına yönelik çalışmaların yapılması önerilebilir. Çalışmalarda, öğretmen adaylarına FeTeMM uygulamalarına yönelik fırsatlar sağlanması, teknoloji ve mühendislik becerilerini hakim oldukları alan bilgilerine entegre ederek, eğitim fakültelerinden mezun olmadan önce deneyim kazanmaları gerektiğinin ifade edildiği görülmektedir. FeTeMM eğitimi kültürünün yerleşmesi için eğitim sürecinin en alt seviyesinden itibaren her dönemde bu eğitimin uygulamalı olarak gerçekleştirilmesi gerekmektedir. Örneğin FeTeMM eğitimi yenlikçi öğrenme ortamlarına örnek olarak Microsoft Uçuş Simulatörü ve Google Earth programları gibi öğretim düzeyine uygun olarak uygulamalardan yararlanılabilir (Çorlu, 2014). Yapılan çalışmaların genellikle nitel çalışmalar olmasının yanında, nicel olarak gerçekleştirilen çalışmaların türlerinin deneysel çalışmalar olduğu görülmektedir. Bu çalışmaların sayıca artması ve FeTeMM uygulamalarının ders içinde kullanımına yönelik öğretmen adaylarıyla birlikte öğretmenlerin bilgilenmesi amacıyla uygulamalı etkinlikler geliştirilmesi ve ilgili kitlenin görüşlerinin de alınmasının yararlı olabileceği düşünülmektedir.

Mevcut öğretim programındaki teknoloji ve mühendislik altboyutlarını destekleyecek seçmeli ya da uygulamalı derslerin yer alması bu konunun alt yapısının sağıkı olarak oluşması ve ilerlemesine katkı sağlayacağı düşünülmektedir. Uygulamalı çalışmalardaki nitel araştırma yöntemlerinin sayıca üstünlüğü göze çarpmaktadır. Araştırmada kullanılan veri toplama araçlarının çeşitlerinin yönteme bağlı olarak değiştiği ve geliştirilen proje ya da etkinliklere bağlı olarak geliştirildiği görülmektedir. Dolayısıyla kitlesel ölçümler ve genellemelerin görülmesi amacıyla gerçekleştirilen nicel araştırmaların sayıca artması da önem arz etmektedir. Bu kapsamda gerçekleştirilecek çalışmalar ve buna yönelik ölçme araçlarının geliştirilmesi, konu ile ilgili yapılan ve ölçümlerden elde edilen sonuçların geçerli ve güvenilir olduğu test edilmiş ölçme araçlarının adaptasyon çalışmalarına intiyaç duyulduğu düşünülmektedir. Çalışmaların incelenmesinden elde edilen diğer bir sonuç ise, araştırmalarda ortak bir FeTeMM yaklaşımı algısının bulunmayışından ötürü, uygulamalarda çeşitli farklılıklar bulunduğu ve gerçekleştirilen etkinliklerin içeriğinde ortak bir anlamın ortaya çıkması noktasında karışıklığa neden olduğudur. Bu durumla çalışmaların yöntemlerinin analizi sürecinde de karşılaşılmıştır. İncelenen çalışmaların bazılarında araştırma modelinin türüyle ilgili bilgi verilmemiş olduğu görülmüştür. Bu nedenle ülkemizde gerçekleştirilecek çalışmaların nitelikli ve etkililiğinin artması için, FeTeMM yaklaşımının kuramsal temellerinin ortak bir çerçevede belirlenerek gerçekleştirilecek etkinliklerin uygulamalı örneklerinin bu bağlamda her düzey için ortak paylaşımda sunulacağı platformların oluşturulması önerilebilir. Aynı zamanda bu konuyla ilgili çalışmaların etkililiğinin test edilmesi proje ve teşviğe yönelik daha fazla kaynağın sağlanması ve yapılan çalışmaların uzun soluklu olarak yürütülmesi önerilmektedir. FeTEMM yaklaşımındaki boyutların içeriğinin detaylı olarak açıklanması yararlı olabilir. Bu bağlamda uygulamalı olarak derslerle kaynaştırılarak sunulması özellikle mühendislik becerisinin gelişmesine yönelik etkinliklerin tasarlanması ve bu çalışmaların etkililiğinin nedensel ve boylamsal araştırma yöntemleri ile test edildiği çalışmaların sayısının artmasının önemli olduğu düşünülmektedir. Bu doğrultuda, öğrencilerde özellikle yaratıcılık becerisinin ön plana çıkması gerektiği vurgulanarak, 
eğitim öğretim sürecinde yürütülecek etkinliklerin bu husus göz önüne alınarak hazırlanması ve teşvik edilmesi önerilebilir.

\section{Kaynakça}

Akgündüz, D. (2016). A research about the placement of the top thousand students in STEM fields in Turkey between 2000 and 2014. Eurasia Journal of Mathematics, Science \& Technology Education, 12(5), 1365-1377.

Baran, E., Canbazoğlu-Bilici, S. ve Mesutoğlu, C. (2015). Fen, teknoloji, mühendislik ve matematik (Fetemm) spotu geliştirme etkinliği. Araştırma Temelli Etkinlik Dergisi, 5(2), 60-69.

Bozkurt-Altan, E. ve Ercan, S. (2016). STEM education program for science teachers: perceptions and competencies. Journal of Turkish Science Education. 13(Special Issue), 103-117.

Bozkurt, E. (2014). Mühendislik Tasarım Temelli Fen Eğitiminin Fen Bilgisi Öğretmen Adaylarının Karar Verme Becerisi, Bilimsel Süreç Becerileri Ve Sürece Yönelik Algılarına Etkisi. Yayınlanmamış Doktora Tezi, Gazi Üniversitesi Eğitim Bilimleri Enstitüsü, Ankara.

Bybee, R. (2010). Advancing STEM education: A 2020 vision. Technology and Engineering Teacher, $7(1), 30-35$.

Çorlu, M. S., Capraro, R. M. ve Capraro, M. M. (2014). Introducing STEM education: Implications for educating our teachers for the age of innovation. 39(171),74-85.

Çorlu, M. S. (2014). FeTeMM eğitimi makale çağrı mektubu. Turkish Journal of Education. 3(1), 4-10.

Ercan, S., Bozkurt Altan, E., Taştan, B. ve Dağ, İ. (2015). Integrating GIS into Science Classes to Handle STEM Education. Journal of Turkish Science Education. 13(Special Issue), 30-43.

Gencer, A. S. (2015). Fen eğitiminde bilim ve mühendislik uygulaması: Fırıldak Etkinliği. Araştırma Temelli Etkinlik Dergisi (ATED), 5(1), 1-19, 2015.

Henderson, C., Beach, A. ve Finkelstein, N. (2011). Facilitating change in undergraduate STEM instructional practices: An analytic review of the literature. Journal of Research in Science Teaching, (48)8, 952-984.

Jayarajah, K., Mohd Saat, R. ve Abdul Rauf, R. (2014). A review of science, technology, engineering \& mathematics (STEM) education research from 1999-2013: A Malaysian perspective. Eurasia Journal of Mathematics, Science \& Technology Education, 10(3), 155-163.

Karahan, E. ve Canbazoğlu-Bilici, S. (2014). Fen Teknoloji Mühendislik ve Matematik (FeTeMM) Eğitimi. Özgül Keleş (Ed.) Uygulamalı Etkinliklerle Fen Eğitiminde Yeni Yaklaşımlar. (s.95). Pegem: Ankara.

Marino, M. T., Black, A. C., Hayes, M. T. ve Beecher, C. C. (2010). An analysis of factors that affect struggling readers' achievement during a technology-enhanced STEM astronomy curriculum. Journal of Special Education Technology, 25(3), 35.

Milli Eğitim Bakanlığı. (2013a). Pisa 2012 Ulusal Ön Raporu. Ankara, Yenilik ve Eğitim Teknolojileri Genel Müdürlüğü.

Milli Eğitim Bakanlığı. (2013b). Illköğretim Kurumları (ilkokullar ve Ortaokullar) Fen Bilimleri Dersi $(3,4,5,6,7$ ve 8. Sınıflar) Öğretim Programı. Ankara, Talim ve Terbiye Kurulu Başkanlığı. http://ttkb.meb.gov.tr/www/guncellenen-ogretim-programlari-ve-kurul-kararlari/icerik/150.

Milli Eğitim Bakanlığı. (2017). Fen Bilimleri Dersi Öğretim Programı (ilkokul ve Ortaokul 3,4,5,6,7 ve 8. Sinıflar), MEB: Ankara. http://mufredat.meb.gov.tr/

National Research Council. (2005). How students learn: History, science, and mathematics in the classroom. Washington, DC: National Academies Press.

National Research Council. (2011). A Framework for K-12 Scence Education: Practices, crosscutting concepts, and core ideas. Washington, DC: National Academies Press.

National Research Council. (2011). A Framework for K-12 Scence Education: Practices, crosscutting concepts, and core ideas. Washington, DC: National Academies Press 
OECD (2016). PISA 2015 results (Volume II): Policies and practices for successful schools. Paris: OECD Publishing.

Pitt, J. (2009). Blurring the boundaries - STEM education and education for sustainable development. Design and Technology Education: An International Journal, 14(1), 37-48.

Roberts, A. ve Cantu, D. (2012). Applying STEM instructional strategies to design and technology curriculum. Proceedings of the Technology Education in the 21st Century, Stockholm; Sweden. 111-118.

Şahin, A., Ayar, M. C. ve Adıgüzel, T. (2014). Fen, teknoloji, mühendislik ve matematik içerikli okul sonrası etkinlikler ve öğrenciler üzerindeki etkileri. Kuram ve Uygulamada Eğitim Bilimleri. 14(1) 297-322.

Wagner, T. (2008). Rigor redefined. Educational Leadership, 66(2), 20-24.

Yıldırım, A. ve Şimşek, H. (2013). Sosyal bilimlerde nitel araştırma yöntemleri. 9. baskı, Seçkin. Ankara.

\section{Alanyazın Taramasına Dahil Edilen Çalışmalar}

Akgunduz, D. (2016). A research about the placement of the top thousand students in STEM fields in Turkey between 2000 and 2014. Eurasia Journal of Mathematics, Science \& Technology Education, 12(5), 1365-1377.

Ayar, M.C. (2016). First-hand experience with engineering design and career interest in engineering: An informal STEM education case study. Educational Sciences: Theory \& Practice. 15(6), 1655-1675.

Ayar, M.C. \& Yalvac, B. (2016). Lessons learned: Authenticity, interdisciplinarity, and mentoring for STEM learning environments. International Journal of Education in Mathematics, Science and Technology, 4(1), 31-43.

Baran, E., Canbazoglu Bilici, S., Mesutoglu, C. ve Ocak, C. (2016). Moving STEM beyond schools: Students' perceptions about an out-of-school STEM education program. International Journal of Education in Mathematics, Science and Technology, 4 (1), 9-19.

Baran, E., Canbazoğlu-Bilici, S. ve Mesutoğlu, C. (2015). Fen, teknoloji, mühendislik ve matematik (Fetemm) spotu geliştirme etkinliği. Araştırma Temelli Etkinlik Dergisi, 5 (2); 60-69.

Bozkurt-Altan, E., Yamak, H. ve Buluş-Kırıkkaya, E. (2016). FeTeMM Eğitim yaklaşımının öğretmen eğitiminde uygulanmasına yönelik bir öneri: tasarım temelli fen eğitimi. Trakya Üniversitesi Eğitim Fakültesi Dergisi, 6(2), 212-232.

Bozkurt-Altan, E. ve Ercan, S. (2016). STEM education program for science teachers: perceptions and competencies. Journal of Turkish Science Education. 13(Special Issue), 103-117.

Buyruk, B. ve Korkmaz, Ö. (2016). FeTeMM Farkındalık Ölçeği (FFÖ): Geçerlik ve güvenirlik çalışması. Türk Fen Eğitimi Dergisi. 13 (2), 61-76.

Ceylan, S. ve Özdilek, Z. (2015). Improving a sample lesson plan for secondary science courses within the STEM Education. Procedia-Social and Behavioral Sciences. 177, 223-228.

Corlu, M. S. (2013). Insights into STEM education praxis: An assessment scheme for course syllabi. Educational Sciences: Theory \& Practice, 13(4), 2477-2485.

Corlu, M. S., Capraro, R. M. ve Capraro, M. M. (2014). Introducing STEM education: Implications for educating our teachers for the age of innovation. Eğitim ve Bilim, 39(171),74-85.

Corlu, M. ve Aydin, E. (2016). Evaluation of learning gains through integrated STEM projects. . International Journal of Education in Mathematics, Science and Technology, 4 (1), 21-29.

Corlu, M. S. (2014). FeTeMM Eğitimi Makale Çağrı Mektubu. Turkish Journal of Education. 3 (1), 4-10.

Çınar, S., Pırasa, N., Uzun, N. ve Erenler, S. (2016). The effect of Stem education on pre-service science teachers' perception of interdisciplinary education. Journal of Turkish Science Education, 13(Special Issue), 118-142. 
Çınar, S., Pırasa, N. ve Palic- Sadoglu, G. (2016). Views of science and mathematics pre-service teachers regarding STEM. Universal Journal of Educational Research, 4(6), 1479-1487.

Ercan, S. ve Şahin, F. (2015). The usage of engineering practices in science education: Effects of design based science learning on students' academic achievement. Necatibey Eğitim Fakültesi Elektronik Fen ve Matematik Eğitimi Dergisi, 9(1), 128-164.

Ercan, S., Bozkurt Altan, E., Taştan, B. ve Dağ, ì. (2015). Integrating GIS into science classes to handle STEM education. Journal of Turkish Science Education, 13(Special Issue), 30-43.

Hacıoğlu, Y., Yamak, H. ve Kavak, N. (2016). Pre-Service Science teachers' cognitive structures regarding science, technology, engineering, mathematics (STEM) and science education. Journal of Turkish Science Education. 13(Special Issue), 88-102.

Hacıömeroğlu, G. ve Bulut, A. S. (2016). Integrative STEM teaching intention questionnaire: A validity and relaibility study of the Turkish form. Eğitimde Kuram ve Uygulama 12(3), 654-669.

Kanlı, E. ve Özyaprak, M. (2015). STEM education for gifted and talented students in Turkey. Journal of Gifted Education Research, 3(2), 1-10.

Karakaya, F. ve Avgın, S. S. (2016). Effect of demographic features to middle school students' attitude towards FeTeMM (STEM). Journal of Human Sciences, 13(3), 4188-4198.

Kertil, M. ve Gürel, C. (2015). Mathematical modeling: A bridge to STEM education. International Journal of Education in Mathematics, Science and Technology. 4(1), 45-55.

Öner, A. T. ve Capraro R. M. (2016). FeTeMM okulu olmak iyi öğrenci başarısı anlamına mı gelir? Eğitim ve Bilim, 41(185),1-17.

Özçakır-Sümen, S. ve Çalışıcı, H. (2016). Pre-service teachers' mind maps and opinions on STEM education implemented in an environmental literacy course. Educational Sciences: Theory \& Practice, 16, 459-476.

Savran-Gencer, A. (2015). Fen eğitiminde bilim ve mühendislik uygulaması: Fırıldak etkinliği. Araştırma Temelli Etkinlik Dergisi (ATED), 5(1), 1-19.

Soylu, Ş. (2016). Stem education in early childhood in Turkey. Journal Of Educational and Instructional Studies In the World. 6(Special Issue 1), 2146-7463.

Şahin, A., Ayar, M. C. ve Adıgüzel, T. (2014). Fen, teknoloji, mühendislik ve matematik içerikli okul sonrası etkinlikler ve öğrenciler üzerindeki etkileri. Kuram ve Uygulamada Eğitim Bilimleri.14 (1), 297-322.

Yamak, H., Bulut, N. ve Dündar, S. (2014). 5. sınıf öğrencilerinin bilimsel süreç becerileri ile fene karşı tutumlarına FeTeMM etkinliklerinin etkisi. Gazi Eğitim Fakültesi Dergisi, 34(2), 249-265.

Yerdelen, S., Kahraman, N. ve Taş, Y. (2016). Low socioeconomic status students' STEM career interest in relation to gender, grade level, and STEM attitude. Journal of Turkish Science Education. 13(Special Issue), 59-74.

Yıldırım, B. ve Selvi, M. (2016). Examination of the effects of STEM education integrated as a part of science, technology, society and environment courses. Journal of Human Sciences. 13(3), 3684-3695. 


\section{Extended Summary}

STEM education is described as composition of scince technology engineering and mathematics which is a new term of the litearature. The goal of the workings are to raise generations with innovation-focused labor force that has 21 st century skills, at all levels of education. Thus, number of studies conducted on this topic all over the world is increasing day by day. This research is aimed at to view studies and dissertations about Science, Technology and Engineering Mathematics Design (STEM) in terms of method and subject trend in Turkey. Therefore, "What kind of methods have been used in the context of STEM education in our country?" and "What are the research topics about STEM education research in our country?" questions are asked. In this direction, thirty articles published by ULAKBIM, ERIC, EBSCOHost, ISI Web of Science and Scopus databases published between August, 2013 and December 2016 and 5 dissertations indexed by National Thesis Center (YÖK) were analyzed by qualilitative descriptive content analysis method in terms of research method, sampling techniques, measurement tools, data collection process and analysis methods. Examined articles showed that, 20 of the articles are applied studies, which of two are scale development and scale adaptation working meanwhile the other examined ones are (10 of them) are based on theoretical. The review of the research shows that quantitative and mixed methods are included in a small number of studies. It has also been found out that the data collection tools used frequently come from events developed by the authors as well. In applied studies, it seems that the activities carried out within the scope of a project concentrate on the academic success, attitude, interest and opinions on the study group concerned. It is seen that activities developed based on the STEM approach are aimed to raise awareness of teachers and teacher candidates and to detect perceptions of their competency status. Although most of them includes qualitative research methods, quantitative and mixed methods are used in a few.

When the research designs are analysed, it is seen that nearly half of them (7 of the studies) have no information about designation types. The other studies are designed as case study, others one for each explanatory composite design, embedded pattern and phenomenological research design in qualilitative paradigm. In accordance with quantitive paradigm, 3 survey method and only one pre-test post-test single-group experimental design research carried on.

The study group preferences show regarding mostly preferred grup is elementary students and prospective teachers because of these studies conduct with projects. Results show that number of 8 studies are implemented with elementary school students, 7 of them are with prospective teachers, and only one is secondary school students. Furthermore, one of the studies is carried out within the scope of a project with teachers. During the studies, most preferred data collection tools are generally open-ended question forms, interview form or records, field notes, activity evaluation forms besides. Word association test in and project reports, test papers observation, student log used data collection tools apart from these. Usage of likert-type scale data collection tool was used in total 5 studies show that scales are used in limited of STEM publications in Turkey.

When the analysis techniques used in the models were examined, it can be seen that quantitative analyzes were used at 6 of 20 studies. Paired sample T-test and ANOVA were used quantitative parametric analysis techniques, for one study for each. Descriptive statistics were used for 2 studies and factor analysis was used for 2 scale development and adaptation study, additionally. In large part of the articles, which are stated to be of qualitative and mixed method, descriptive and content analyzes were carried out by coding from the documents used in the study and from the findings obtained from the interviews.

Given that STEM studies conducted in Turkey, it can be seen that subject trends of STEM approach activities are based on to examine their effects from various dimensions. In this context, it seems that positive effects are observed in affective dimensions such as attitude, motivation and interest in every level group as well as their academic success, scientific process skills and contribute their 
learning, Especially, the results of studies carried out with middle school students, have shown that students are inclined towards STEM professions in their career choices. In theoretical studies, calls to improve the recognition of STEM education in our country and to develop STEM-based studies are in the foreground.

All in all, it is thought that it is important to design STEM dimensions in the form of practical integration with the courses, in particular to design activities for the development of engineering skills and to increase the number of studies in which the effectiveness of these studies is tested by causal and longitudinal research methods. In this respect, it can be suggested that the students should be encouraged to prepare the activities to be carried out during the education and training process taking into consideration this fact. 